\title{
The Perception of Premarital Genetic Screening within Young Jordanian Individuals
}

\author{
Zaid Altaany $^{\mathrm{a}}$ Omar F. Khabour ${ }^{\mathrm{b}} \quad$ Karem H. Alzoubi $^{\mathrm{c}} \quad$ Almuthanna K. Alkaraki $^{\mathrm{d}}$ \\ Ghaith Al-Taani ${ }^{\mathrm{e}}$

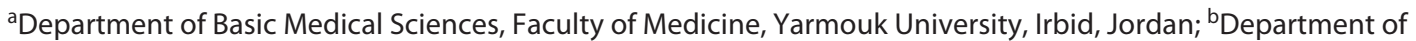 \\ Medical Laboratory Sciences, Faculty of Applied Medical Sciences, Jordan University of Science and Technology, \\ Irbid, Jordan; 'Department of Clinical Pharmacy, Faculty of Pharmacy, Jordan University of Science and Technology, \\ Irbid, Jordan; dDepartment of Biological Sciences, Faculty of Science, Yarmouk University, Irbid, Jordan; \\ eDepartment of Pharmacy Practice, Faculty of Pharmacy, Yarmouk University, Irbid, Jordan
}

\section{Keywords}

Premarital genetic screening $\cdot$ Genetic counseling $\cdot$ Jordan genetic screening.

\begin{abstract}
Background: During the past two decades, the attention of public health has been drawn to premarital genetic screening (PGS) programs to reduce birth defects and avoid genetic disorders. In Jordan, the high rate of genetic hemoglobinopathies compelled the government to implement an obligatory PGS program before marriage. Therefore, the objective of this study was to investigate the knowledge, opinion, and practice of young Jordanians concerning PGS. Methods: Using a pretested questionnaire, this cross-sectional study was conducted on a convenience sample from Jordan. The measures included respondents' demographics, and beliefs/opinions regarding PGS. Results: A total of 432 participants completed the survey. The majority $(87.8 \%)$ had a positive attitude toward PGS program. Reasons behind this positive attitude were preventing transmission of genetic diseases, reducing family breakdown/psychosocial problems, and financial burdens of having a child with genetic disease. In fact, $49.8 \%$ of participants were willing to change
\end{abstract}

karger@karger.com www.karger.com/phg

Karger $\stackrel{\text { ' }}{5}$

GOPEN ACCESS
(C) 2021 The Author(s)

Published by S. Karger AG, Basel

This is an Open Access article licensed under the Creative Commons Attribution-NonCommercial-4.0 International License (CC BY-NC) (http://www.karger.com/Services/OpenAccessLicense), applicable to the online version of the article only. Usage and distribution for commercial purposes requires written permission. their marriage decision in case of receiving incompatible results. Moreover, most of the participants $(75.1 \%)$ demanded the implementation of a law that prohibits incompatible marriages. A positive attitude toward PGS was found to be associated with female gender and having a university education. Conclusions: Young Jordanians have a positive attitude toward the implementation of PGS. Yet, educational programs should be drawn up to the target population before getting married emphasizing the important role of PGS in the wellness of the community.

(c) 2021 The Author(s) Published by S. Karger AG, Basel

\section{Introduction}

Genetic screening refers to explicit and systematic programs directed either at a whole population of asymptomatic individuals or at subpopulations in which risk is known to be increased [1]. World Health Organization (WHO) recommends population-wide screening tests for diseases with serious consequences, where screening tests showed potential benefits and advantages to people's health [2]. 
Premarital genetic screening (PGS) helps to avoid hereditary diseases; thus, increasing the likelihood of having a happy and stable family. Consanguineous marriages are common in the Middle East and North Africa (MENA) region. As a consequence, the prevalence of genetic abnormalities in the MENA is high. For example, the rate of heterozygosity (carriers) for glucose-6-phosphate dehydrogenase (G6PD) deficiency is between $2.5 \%$ and $27 \%$, and for thalassemia/sickle cell anemia is between $30 \%$ and $50 \%$ [3]. In recent years, several countries in the MENA region have implemented mandatory PGS programs to stem the prevalence of genetic disorders $[4,5]$. The majority of such PGS aims to identify carriers of hemoglobin disorders, in order to assess the risk of having children with a severe form of the disease. A meta-analysis of 23 well-designed premarital prevention programs revealed that such programs are effective and efficient in yielding immediate and short-term gains in terms of the wide spectrum of relationships [6].

In Jordan, the government established a PGS program in 2007 to lower the prevalence of hemoglobinopathies, especially thalassemia $[7,8]$. The mandatory PGS is provided for free to all Jordanians in public hospitals and health-care centers, and a test certificate is required to complete the marriage procedures. Genetic counseling is also provided to incompatible couples which explain the results of the screening and the available options. The PGS can be effective for the prevention and management of congenital anomalies and associated psychosocial marital problems [9].

Mandatory PGS programs began in the 1970s to eradicate $\beta$-thalassemia in the Mediterranean region. Cyprus took the initiative and implemented a PGS program in 1973 with a very successful story. The program was able to decrease the annual number of affected births from 51 to 8 between 1974 and 1979 and to 0 since 2002 [10]. Similar programs were implemented in Italy and Greece which also achieved $100 \% \beta$-thalassemia birth reductions [11]. However, the attitude and knowledge of the populations in the Arab region regarding PGS need attention. Thus, the present study aimed to examine both the knowledge and attitudes of Jordanians, as an example of Arab populations, who are at marriage age toward PGS.

\section{Methods}

Questionnaire Setup, Ethical Approvals, and Data Collection

This questionnaire-based study was carried out to survey young Jordanian adults. The content of the questionnaire was planned corporately between the investigators based on previous
Table 1. Demographic and background characteristics of the respondents

\begin{tabular}{ll}
\hline Variable & $\%(n) /$ mean \\
\hline Age, years & 21.7 \\
\hline Gender & \\
Male & $29.9(129)$ \\
Female & $70.1(303)$ \\
\hline Education & \\
Less than high school & $0.9(4)$ \\
Up to high school & $13.7(59)$ \\
University students & $85.4(369)$ \\
\hline
\end{tabular}

similar studies in genetics-related practice and research. The developed questionnaire was peer-reviewed by other faculty members and was pretested and piloted on 10 participants, who were not included in the final data analysis of the study, to provide feedback about clarity and comprehensibility of the questions. Feedback from the pilot testing was taken into considerations, and the suggested adjustments were incorporated into the questionnaire.

Ethical approval was obtained from the Jordan University of Science and Technology IRB committee. Voluntary participation of subjects has been confirmed through an Arabic written informed consent form before data collection. All procedures, data storage, and privacy concerns were governed by the ethical regulations of Jordan University of Science and Technology and Yarmouk University (Irbid, Jordan).

The Arabic form of the questionnaire was distributed by hand to a convenience sample of young adults in the Northern part of Jordan ( $\geq 18$ years old) who were at shopping centers or universities by a well-trained research assistant. The research assistant approached the potential participants and explained the elements of the study to them making sure that they were single or at the marriage age. After sufficient consideration, only those who agreed to take part in the study were allowed to fill the questionnaire. The response rate was $61 \%$. Recruitment was continued until the target sample size was reached 432 responses, $5 \%$ margin of error; $95 \%$ confidence interval. The study questionnaire was developed to target the demographic characteristics and premarriage genetic testing beliefs among adult Jordanian subjects. The demographic characteristics included age, gender, and education. Premarriage genetic testing questions covered beliefs, the timing of genetic testing, aims, benefits, and risks of PGS.

\section{Data Analysis}

Data were analyzed using Statistical Package for Social Sciences (SPSS), version 22.0 (IBM Corporation, Armonk, NY, USA). Values were expressed via employing frequencies, percentages, and means. $\chi^{2}$ analysis and independent samples $t$ test were used to assess the association among outcomes. Statistical significance was considered once $p$ value $\leq 0.05$. 
Fig. 1. Beliefs about the purpose and decisions after PGS results. PGS, premarital genetic screening.

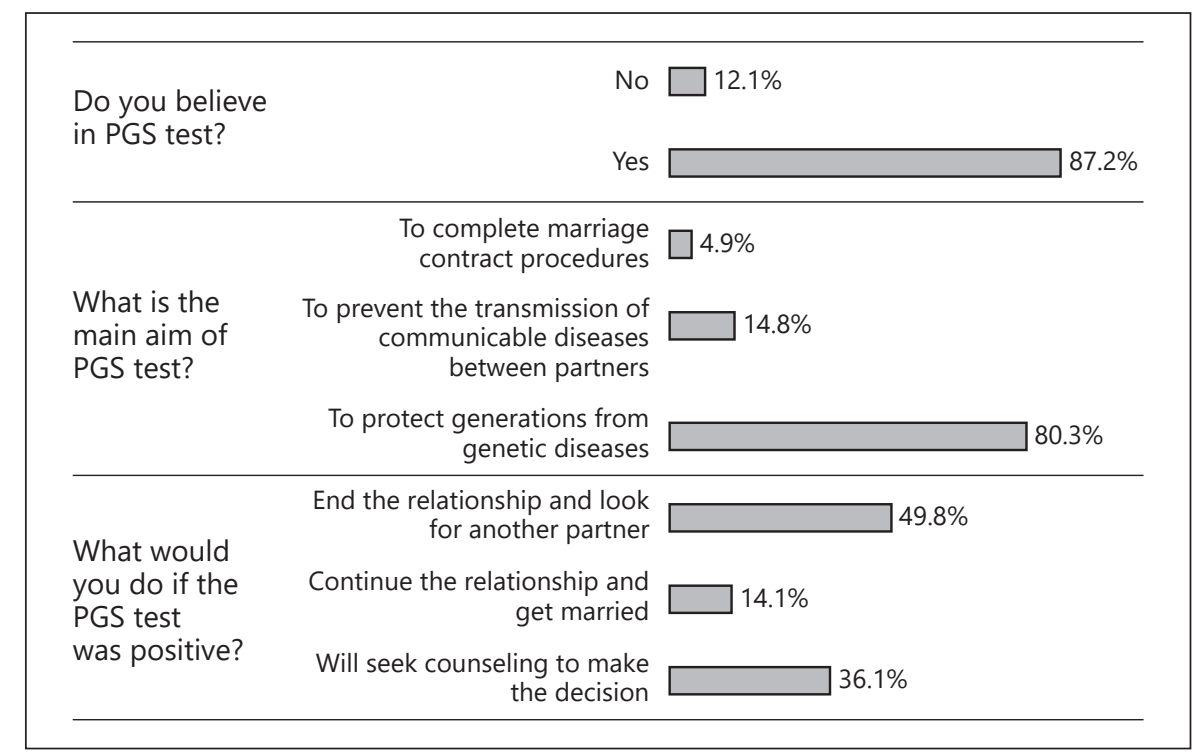

\section{Results}

\section{Sample Characteristics}

The survey was completed by 432 respondents who were laypersons from Irbid, a large city in the North of Jordan. The mean age of the sample was 21.7 years. About $70 \%$ of the study participants were females, and $85.4 \%$ of them were university students/university graduates. A minority of the respondents $(0.9 \%)$ education was less than high school. The full details of the demographic and background characteristics are summarized in Table 1.

\section{Beliefs and Obligations of Young Jordanian to PGS}

Figure 1 displays some of the issues of PGS about beliefs, timing, aims, and obligations. An indicator of positive beliefs regarding PGS was noted. The majority of the respondents $(87.8 \%)$ believed in the vitality and necessity of PGS. Yet $12.1 \%$ did not believe that PGS is essential. Overall, when looking at the purpose of PGS, more than three-quarters $(80.3 \%)$ of the respondents elucidated that the main aim of PGS was to protect future generations from genetic diseases and disorders. Still, $14.8 \%$ of the respondents believed that the goal of PGS is to prevent the transmission of communicable diseases from partner to partner.

\section{Expected Consequences of Positive PGS}

When respondents were asked about their attitudes towards the PGS results, half of them (49.8\%) indicated that they would end their relationship in the case of receiving incompatible or abnormal test results. Besides, $36.1 \%$ of
Table 2. Opinions of respondents regarding items related to PGS

\begin{tabular}{lcc}
\hline Variable & Percent & $(n)$ \\
\hline Do you think PGS should be obligatory? & \\
Yes & 88.3 & 385 \\
No & 11.7 & 51
\end{tabular}

The government should enforce individuals to stop the proposed marriage if the result of PGS is positive.

$\begin{array}{lll}\text { Yes } & 75.1 & 325 \\ \text { No } & 24.9 & 108\end{array}$

PGS is useful and can reduce family breakdown and future psychosocial problems.

$\begin{array}{lll}\text { Yes } & 86.7 & 376 \\ \text { No } & 13.3 & 58 \\ \text { GS is considered prohibited according to my beliefs. } & \\ \text { Yes } & 13.1 & 57 \\ \text { No } & 86.9 & 377\end{array}$

PGS should be expanded to include other genetic diseases if the proposed partners have a family history of genetic diseases.

$\begin{array}{lll}\text { Yes } & 84.1 & 366 \\ \text { No } & 15.9 & 69\end{array}$

PGS can minimize the economic burden of genetic diseases in the country.
Yes
82.0
355
No
18.0
78

PGS, premarital genetic screening.

them reported that they would seek genetic counseling to help them decide their relationship. On the other hand, about $14.1 \%$ of the respondents indicated that they would continue the relationship and get married. 
Table 3. Factors associated with different beliefs related to PGS

\begin{tabular}{|c|c|c|c|c|}
\hline \multirow{2}{*}{$\begin{array}{l}\text { Variable } \\
\text { Gender }\end{array}$} & \multicolumn{2}{|c|}{$\begin{array}{l}\text { Do you support } \\
\text { that the PGS being } \\
\text { obligatory }\end{array}$} & \multicolumn{2}{|c|}{$\begin{array}{l}\text { Do you think that } \\
\text { PGS is useful and } \\
\text { limit the spread of } \\
\text { diseases }\end{array}$} \\
\hline & & & & \\
\hline Male & 82.0 & 0.010 & 83.5 & 0.008 \\
\hline Female & $90.8^{*}$ & & $92.0^{*}$ & \\
\hline \multicolumn{5}{|l|}{ Education } \\
\hline Less than high school & 75.0 & $<0.001$ & 75.0 & $<0.001$ \\
\hline Up to high school & 49.2 & & 69.0 & \\
\hline \multicolumn{5}{|l|}{ University students/ } \\
\hline University degree & 94.8 & & 92.9 & \\
\hline
\end{tabular}

* $p$ value $\leq 0.05$. PGS, premarital genetic screening.

\section{Opinions of Young Jordanian to PGS}

Table 2 summarizes the opinions of respondents regarding PGS. Results further confirmed the positive attitude of the respondents regarding PGS. A high percentage of the respondents believed that PGS should be obligatory (88.3\%), and the government should use its power to stop the marriage if PGS result is positive $(75.1 \%)$ as a preventive measure to restrict the spread of genetic diseases. Additionally, the majority agreed that PGS can minimize the economic burden of treating the genetic diseases in the country (82.0\%), significantly reduce family breakdown, and prevent future psychosocial problems $(86.7 \%)$. Finally, the majority $(84.1 \%)$ of participants agreed that PGS should be expanded to include other genetic diseases if the concerned partners have a family history of genetic diseases. However, about $13.1 \%$ of participants believed that PGS is legally forbidden.

\section{Attitudes Related to PGS}

Table 3 identifies different factors associated with attitudes related to PGS. Attitude toward the availability and use of PGS was assessed using the statements like "Do you support that the PGS should be obligatory?"; and "Do you think that PGS is useful and can limit the spread of diseases?." The findings show that being a female and having a university degree were associated with a positive attitude toward PGS $(p<0.05)$.

\section{Discussion}

The PGS is implemented by many governments to limit the spread of hemoglobinopathies and other inherited genetic disorders in their populations by identifying those who are at increasing risk, thereby enabling individuals to receive information about the potential health of their offspring [12]. Sickle cell anemia in the USA, TaySachs disease among Ashkenazi Jews, and thalassemia in the Mediterranean region were among the first examples of severe diseases for which general screening programs were offered to delineated populations [13]. Worldwide guidelines recommend that genetic screening should not be compulsory for any individual or population, and appropriate information should be provided to individuals before testing to enable informed decision-making about genetic screening and delivering proper accompanied counseling [10].

The current study revealed that the majority of young individuals in Jordan believed in and appreciated the importance of PGS programs in protecting future generations from genetic diseases. This was based on their wish to prevent the transmission of disease to their offspring. In fact, the majority of respondents from the current study believed that PGS could reduce the financial burden of genetic diseases in the country. Furthermore, they viewed that PGS can reduce family breakdown and psychosocial problems. These observed positive attitudes toward PGS and its benefits are consistent with other published studies [14]. An interesting study on the Italian genetic testing consumers showed awareness, responsibility, and motivation among respondents toward their health, they wanted to reduce uncertainty for future risks and believed that genetic testing can help them to take steps in these directions [15]. A new cross-sectional study developed by Dutch researchers conducted in four European nations showed that the Hungarian citizens had the most positive opinion on the personal benefits of genetic testing followed by the Czech, Slovak, and Polish [16]. In a systematic review that included forty-one studies (39 from the USA, and 2 from Australia), the attitudes toward genetic testing were generally positive; perceived benefits included positive implications for personal health; and being able to inform family [17]. In a survey that included 560 women who had been offered prenatal screening in Ontario, the participants strongly supported the clinical utility of genetic testing in the diagnosis and management of diseases [18]. Similar positive attitude toward genetic testing was reported among Framingham Heart Study participants [19] and German population [20]. Thus, studies conduct worldwide showed positive attitude of people toward clinical uses of genetic testing to improve health-care services and prevention of diseases.

In the current study, a small percentage of respondents indicated that they would continue the proposed mar- 
riage and would take the risk of having children with a hereditary disease. A study from Oman revealed that onethird of the study population reported that they were not in favor of taking PGS [21]. Another study that was conducted in Oman on university students showed that a small fraction (5\%) declined or were not sure of implementing PGS [22]. Thus, a fraction of the population might underestimate the devastating psychological and financial burden of genetic diseases on the family and the community. Alternatively, the psychological impact of genetic tests that are focused on "harmful" reactions, such as anxiety, distress, and depression, when receiving genetic risk information might be the reason behind their negative perception regarding PGS $[22,23]$. This fraction of the population might also have insufficient knowledge regarding genetic testing and PGS. In support of this, the positive attitude toward genetic testing has been shown to be associated with knowledge about genetic diseases and genetic testing [24]. In addition, the incorporation of PGS-related information into high school health packages as in the case of India and Canada, or as part of the university entry along with health education on hereditary diseases and consanguineous marriages could enhance the positive perception about PGS in the population [25]. The lack of knowledge about genetic testing was reported in some countries from the region. For example, a study showed that Syrian university students had insufficient knowledge about genetic inheritance and the purposes of PGS [14]. Another study from Qatar that was performed in hospitals and primary health-care centers showed that the knowledge and attitude regarding PGS were low in the population and attributed this to the lack of motivation and enforcement of the PGS program [26]. Finally, the negative perception about PGS by some of the respondents could be related to due to religious or personal reasons [22]. Thus, a variety of factors might contribute to the reported negative perception of PGS in the region. Indeed, political and eugenic ends must be excluded, and it should be recognized that PGS does not aim at the perfection of human beings. However, under certain circumstances, PGS can lead to an argument that couples should make reproductive decisions favoring particular genetic characteristics, which may be considered as a form of eugenics.

In the current study, the majority of responders believe that governments should step in and enforce individuals to stop their planned marriage if PGS results are positive. Furthermore, the majority thinks that PGS should be obligatory. These findings are similar to other studies conducted in some other countries in the region. In
Oman, a study showed that fifty percent of the subjects favored obligatory PGS before marriage, and one-third favored law legislations to stop marriage in case of positive results [22]. A population study conducted in Saudi Arabia showed that $42 \%$ of the examined sample recommended the compulsory implementation of PGS. Another study from Saudi Arabia that was done on high school students showed that female subjects were more likely than male ones to support the laws, legislations, and regulations to prevent marriages of people whose PGS tests are positive [27]. There is always an ethical argument regarding reproductive decisions of at-risk individuals for genetic diseases, and it should be left for the individual to choose. In addition, reproductive autonomy can fluctuate within different relationships and cultural contexts, depending on the degree to which the partner or surrounding community supports reproductive rights [28]. Prevention and autonomy are two different aspects of preconception care for individual couples with increased genetic risk [29]. They aim to prevent the birth of carrier/ affected individuals, thereby reducing societal costs (health economy). They also can be motivated by ethical prevention of suffering from horrible pregnancy outcomes for mother and child [29].

In Arab countries, marriage decision traditionally is not limited to the couple's choice alone; familial influence plays a major role in whether a couple will get married or not. Therefore, creating a legal basis on which to prevent marriages may get in conflict with popular traditions and customs. Consequently, massive campaigns and legal support would be required to improve compliance with health-care team recommendations, especially for individuals with a family history of genetic disorders [27]. On the other hand, some couples might decide not to have children if PGS result is positive and prefer to proceed with their proposed marriage. In this context, having a law that legalizes the stop of a proposed marriage might lead to conflict with individual rights. Therefore, any regulations should have to balance between individuals' rights or autonomy and the benefits of the community. The PGS might be offered to individuals in the community as a service, and no pressure should be applied to persuade people to cooperate out of a sense of public duty. In this case, it is critical to assess the impact of PGS on society as the occurrence of diseases that are tested by PGS results in the need for long-term treatments and care, increases the use of health professionals, and gets access to medical equipment and medications. The genetic disease is regarded as a high burden on society, including the psychological benefit of PGS for at-risk indi- 
viduals for a particular disease which they know from their own family is the reduction of anxiety [30,31].

A positive attitude toward PGS was found to be associated with being female and having a university education. In a study from Oman, attitude toward PGS was associated with gender, age, marital status, education level, and income [21]. In the Arab community, females are always blamed by the husband's family for the negative outcomes of the pregnancy. Therefore, the observed association between attitude toward PGS and being female is in accordance with this norm and is consistent with a study that was conducted in Oman [21]. The observed association with university education is in harmony with a study that was conducted in Saudi Arabia [5] and Turkey [26]. The impact of education on the willingness to undergo genetic testing, in general, is well documented [32-35]. Therefore, enhancing awareness about the importance of genetic testing can improve the acceptance of PGS in the populations.

In conclusion, the overall finding of the current study shows a positive attitude among young Jordanian participants toward PGS. The results revealed that the majority of the participants believed in its effectiveness in the prevention of genetic diseases. Most of the participants were also convinced that PGS should be mandatory and believed that PGS decreased the economic burden and psychosocial problems of future families. Overall being female and having a university education were factors associated with a positive attitude towards PGS.

This work is exploratory and subject to some limitations in terms of representativeness. Given the narrow research area and the research questions, the overall target group is very small. We cannot generalize our results to the broader population, but we can assume that they are somewhat representative of the overall small target group. Furthermore, the PGS is the category of genetic testing for fertility and reproduction on which our current study focuses, but there are other main categories of genetic testing such as fertility testing, HIV-PGS, preimplantation genetic diagnosis which are conductive and fertile field for further investigation.

\section{Acknowledgements}

Workonthisprojectwassupportedbygrant\#5R25TW010026-02 from the Fogarty International Center of the US National Institutes of Health. In addition, the authors would like to thank the Deanship of Research and Graduate Studies at Yarmouk University for its support, and Jordan University of Science and Technolgy (JUST).

\section{Statement of Ethics}

All procedures followed were in accordance with the ethical standards (Declaration of Helsinki, 1975), as revised in 2000 (5). Informed consent was obtained from all subjects who participated in this study. The study was approved by the Institutional Review Board Committee \# (17/122/2019) at Jordan University of Science and Technology - Irbid - Jordan.

\section{Conflict of Interest Statement}

The authors have no conflicts of interest to declare.

\section{Funding Sources}

Workonthisprojectwassupportedbygrant\#5R25TW010026-02 from the Fogarty International Center of the US National Institutes of Health, Yarmouk University, Jordan University of Science and Technology (JUST).

\section{Authors Contributions}

Z.A, O.F.K., and G.A.-T. designed the study. G.A.-T. and Z.A. analyzed the data. K.H.A, A.K.A., O.F.K., G.A.-T., and Z.A. wrote the manuscript. Z.A., O.F.K., K.H.A., and A.K.A. contributed to the interpretation of the results. K.H.A. and O.F.K. conceived the study and were in charge of overall direction and planning.

\section{References}

1 Godard B, ten Kate L, Evers-Kiebooms G, Aymé S. Population genetic screening programmes: principles, techniques, practices, and policies. Eur J Hum Genet. 2003;11(Suppl 2):S49-87.

2 El-Hazmi MA. Pre-marital examination as a method of prevention from blood genetic disorders. Community views. Saudi Med J. 2006; 27(9):1291-5.
3 Hamamy H. Community genetic services in Arab countries. Middle East J Med Genet. 2013;2(1):6-10.

4 Al-Allawi NA, Jalal SD, Ahmed NH, Faraj AH, Shalli A, Hamamy H. The first five years of a preventive programme for haemoglobinopathies in Northeastern Iraq. J Med Screen. 2013;20(4):171-6.
5 Ibrahim NK, Al-Bar H, Al-Fakeeh A, Al Ahmadi J, Qadi M, Al-Bar A, et al. An educational program about premarital screening for unmarried female students in King Abdul-Aziz University, Jeddah. J Infect Public Health. 2011;4(1):30-40.

6 Carroll JS, Doherty WJ. Evaluating the effectiveness of premarital prevention programs: a meta-analytic review of outcome research. Fam Relat. 2003;52(2):105-18. 
7 Teebi AS. Genetic disorders among Arab populations. Heidelberg, Germany: Springer Science \& Business Media; 2010.

8 El-Shanti H. The impact of genetic diseases on Jordanians: strategies towards prevention. J Biomed Biotechnol. 2001;1(1):45-7.

9 Al Sulaiman A, Suliman A, Al Mishari M, Al Sawadi A, Owaidah TM. Knowledge and attitude toward the hemoglobinopathies premarital screening program in Saudi Arabia: population-based survey. Hemoglobin. 2008; 32(6):531-8.

10 Cousens NE, Gaff CL, Metcalfe SA, Delatycki MB. Carrier screening for beta-thalassaemia: a review of international practice. Eur J Hum Genet. 2010;18(10):1077-83.

11 Saffi M, Howard N. Exploring the effectiveness of mandatory premarital screening and genetic counselling programmes for $\beta$-Thalassaemia in the middle east: a scoping review. Public Health Genom. 2015;18(4): 193-203.

12 Mennuti MT. Genetic screening in reproductive health care. Clin Obstet Gynecol. 2008; 51(1):3-23.

13 Zlotogora J. Population programs for the detection of couples at risk for severe monogenic genetic diseases. Hum Genet. 2009;126(2): $247-53$.

14 Gharaibeh H, Mater FK. Young Syrian adults knowledge, perceptions and attitudes to premarital testing. Int Nurs Rev. 2009;56(4): $450-5$.

15 Oliveri S, Durosini I, Cutica I, Cincidda C, Spinella F, Baldi M, et al. Health orientation and individual tendencies of a sample of Italian genetic testing consumers. Mol Genet Genom Med. 2020;8(8):e1291.

16 Bíró K, Dombrádi V, Fekete Z, Bányai G, Boruzs K, Nagy A, et al. Investigating the knowledge of and public attitudes towards genetic testing within the Visegrad countries: a cross-sectional study. BMC Public Health. 2020;20(1):1380.
17 Hann KEJ, Freeman M, Fraser L, Waller J, Sanderson SC, Rahman B, et al. Awareness, knowledge, perceptions, and attitudes towards genetic testing for cancer risk among ethnic minority groups: a systematic review. BMC Public Health. 2017;17(1):503

18 Etchegary H, Cappelli M, Potter B, Vloet M, Graham I, Walker M, et al. Attitude and knowledge about genetics and genetic testing. Public health genomics. 2010;13(2):80-8.

19 Saylor KW, Ekunwe L, Antoine-LaVigne D, Sellers DE, McGraw S, Levy D, et al. Attitudes toward genetics and genetic testing among participants in the Jackson and Framingham Heart Studies. J Empir Res Hum Res Ethics. 2019;14(3):262-73.

20 Balck F, Berth H, Meyer W. Attitudes toward genetic testing in a german population. Genet Test Mol Biomarkers. 2009;13(6):743-50.

21 Al-Farsi OA, Al-Farsi YM, Gupta I, Ouhtit A, Al-Farsi KS, Al-Adawi S. A study on knowledge, attitude, and practice towards premarital carrier screening among adults attending primary healthcare centers in a region in Oman. BMC Public Health. 2014;14(1):380.

22 Al Kindi R, Al Rujaibi S, Al Kendi M. Knowledge and attitude of university students towards premarital screening program. Oman Med J. 2012;27(4):291-6.

23 Oliveri S, Pravettoni G. The disclosure of direct-to-consumer genetic testing: sounding out the psychological perspective of consumers. Biol Med. 2016;8(5).

24 Stevens EM, Patterson CA, Tchume-Johnson T, Antiel RM, Flake A, Smith-Whitley K, et al. Parental attitudes towards prenatal genetic testing for sickle cell disease. J Pediatr Hematol Oncol. 2019;41(8):579-85.

25 Petrou M. Screening for beta thalassaemia. Indian J Hum Genet. 2010;16(1):1-5.

26 Bener A, Al-Mulla M, Clarke A. Premarital screening and genetic counseling program: studies from an endogamous population. Int J Appl Basic Med Res. 2019;9(1):20-6.
27 Al-Kindi RM, Kannekanti S, Natarajan J, Shakman L, Al-Azri Z, Al-Kalbani NI. Awareness and attitude towards the premarital screening programme among high school students in Muscat, Oman. Sultan Qaboos Univ Med J. 2019;19(3):e217-e24.

28 Upadhyay UD, Dworkin SL, Weitz TA, Foster DG. Development and validation of a reproductive autonomy scale. Stud Fam Plann. 2014;45(1):19-41.

29 Buchanan DR. Autonomy, paternalism, and justice: ethical priorities in public health. Am J Public Health. 2008;98(1):15-21.

30 Wiggins S, Whyte P, Huggins M, Adam S, Theilmann J, Bloch M, et al. The psychological consequences of predictive testing for Huntington's disease. Canadian Collaborative Study of Predictive Testing. N Engl J Med. 1992;327(20):1401-5.

31 Altaany Z, Khabour OF, Al-Taani G. Knowledge, beliefs, and attitudes concerning genetic testing among young Jordanians. J Multidiscip Healthc. 2019;12:1043-8.

32 Abdul Rahim HF, Ismail SI, Hassan A, Fadl T, Khaled SM, Shockley B, et al. Willingness to participate in genome testing: a survey of public attitudes from Qatar. 2020;65:106773.

33 Canedo JR, Miller ST, Myers HF, Sanderson M. Racial and ethnic differences in knowledge and attitudes about genetic testing in the US: systematic review. J Genet Couns. 2019;28(3): 587-601.

34 Manchanda R, Burnell M, Gaba F, Sanderson S, Loggenberg K, Gessler S, et al. Attitude towards and factors affecting uptake of population-based BRCA testing in the Ashkenazi Jewish population: a cohort study. BJOG. 2019;126(6):784-94.

35 Metcalfe SA. Genetic counselling, patient education, and informed decision-making in the genomic era. Semin Fetal Neonatal Med. 2018;23(2):142-9. 